\title{
The association of urinary uric acid excretion with ambulatory blood pressure values in patients with chronic kidney disease
}

Ying $\mathrm{Xu}^{1,2}$, Xun Zhou ${ }^{1,2}$, Yuqi Zheng ${ }^{1,2}$, Haochen Guan ${ }^{1,2}$, Chensheng $\mathrm{Fu}^{1,2}$, Jing Xiao ${ }^{1,2^{*}}$ and Zhibin Ye $\mathrm{e}^{1,2^{*}}$

\begin{abstract}
Background: To analyze the association between hypertension and urinary uric acid excretion in patients with chronic kidney disease (CKD).

Methods: We screened 87 patients who had been admitted at the Dept of Nephrology, Huadong hospital between April 2017 to April 2019 who had completed 24-h ambulatory blood pressure monitoring and retained 24-h urine biochemical test specimens, thirty adult patients (age $\leq 65$ years) with CKD 1-2 stages were recruited in the study. Pearson's correlation analysis and multiple linear regression analysis were used to study the correlation of urinary uric acid excretion with ambulatory blood pressure values and the association of morning mean diastolic pressure (mMDP), night mean diastolic pressure (nMDP) and CV of dMSP (coefficient of variation of day mean systolic pressure) with fractional excretion of uric acid (FEua) and uric acid clearance rate (Cur). Independent T test was used to compare the differences of blood pressure values in FEua1 (FEua $<6.0 \%$ ) and FEua2 (FEua $\geq 6.0 \%$ ) or Cur1 (Cur $<6.2 \mathrm{ml} / \mathrm{min} / 1.73 \mathrm{~m}^{2}$ ) and Cur2 (Cur $\geq 6.2 \mathrm{ml} / \mathrm{min} / 1.73 \mathrm{~m}^{2}$ ) groups according to the median of FEua or Cur, respectively.
\end{abstract}

Results: After adjusting for confounding factors, multiple linear regression analysis showed that FEua was positively associated with the MMDP and nMDP, Cur was positively associated with CV of dMSP. Levels of mMDP and nMDP in FEua1 group was lower than that in FEua2 group (both $P<0.05$ ), level of CV of dMSP in Cur2 group were higher than that in Cur1 group $(P<0.01)$.

Conclusions: We demonstrated that there is a positive correlation of FEua with morning and night mean diastolic pressure separately and Cur is positively related to CV of dMSP in CKD population. Monitoring the trend of urinary uric acid, may have a role in the early detection for hypertension or relative risks in the population of CKD.

Keywords: Ambulatory blood pressure, Chronic kidney disease, Hypertension, Urinary uric acid

\section{Introduction}

Hypertension (HTN) is quite prevalent in chronic kidney disease (CKD) and is the leading cause of death. The important characteristics of hypertension in CKD are morning blood pressure surge (MBPS) and nocturnal hypertension. Previous studies have shown that MBPS and nocturnal hypertension may increase the risks of cardiovascular event,

\footnotetext{
*Correspondence: jingxiao13@fudan.edu.cn; yezhibin3@126.com ${ }^{1}$ Department of Nephrology, Huadong Hospital Affiliated to Fudan University, No. 221 West Yan'an Road, Shanghai 200040, People's Republic of China Full list of author information is available at the end of the article
}

vascular disease and inflammation and silent cerebrovascular disease $[1,2]$. The related mechanism underlying the phenomena covers several aspects, including the variation of vagal and sympathetic tone across day and night, the activation of renin-angiotensin system early in the morning, the peripheral vascular resistance and urinary sodium and potassium excretion. The variability of blood pressure is able to predict cardiovascular event, but is not associated with absolute blood pressure levels and was not regularly assessed in clinical practice [3]. In recent decades, it has been proved that increased blood pressure variability (BPV)

(C) The Author(s). 2020 Open Access This article is distributed under the terms of the Creative Commons Attribution 4.0 International License (http://creativecommons.org/licenses/by/4.0/), which permits unrestricted use, distribution, and 
directly obtained by 24-h ambulatory BP monitoring (ABPM) was associated with end-organ damage, cardiovascular events, and mortality [4].

Hyperuricemia is also common in CKD, with a prevalence as high as $8.4 \%$ in China [5]. We have found that urinary uric acid excretion is related to urinary sodium and potassium excretion in hypertension with CKD [6]. As is known to all, the secretion and excretion of $\mathrm{Na}^{+}$ and $\mathrm{K}^{+}$are depended on $\mathrm{Na}^{+}-\mathrm{K}^{+}$-ATPase (NKA). In fact, the driving force of urate transporters in renal tubules comes from its basolateral $\mathrm{Na}^{+}-\mathrm{K}^{+}$-ATPase too. Furthermore, the NKA/Src complex has been shown to be activated in the kidney to address excess salt, and the tradeoff could be the development of salt-induced hypertension [7].

Therefore, we made a reasonable hypothesis that urinary uric acid excretion would lead to the abnormality of HTN in CKD. Hence, we study the association of urinary uric acid excretion with ambulatory blood pressure values. In this study, the urinary uric acid excretion indicators are measured in 24-h urinary uric acid (24-hUua), fractional excretion of uric acid (FEua), excretion of uric acid per volume of glomerular filtration (EurGF) and uric acid clearance rate (Cur).

\section{Materials and methods}

\section{Study participants}

In this cross-sectional study, a total of 87 adult patients with CKD admitted to department of nephrology in Huadong Hospital affiliated to Fudan University were collected during two-year period from April 2017 to April 2019, who had completed 24-h ambulatory blood pressure monitoring and retained 24-h urine biochemical test specimens. We eventually recruited 30 patients with two conditions: first, age should be equal or less than 65 years old; second, the damage of renal function is not serious (eGFR $\geq 60 \mathrm{ml} / \mathrm{min} / 1.73 \mathrm{~m}^{2}$ ) (Fig. 1). The conditions for screening CKD was not limited to a single kidney damage, it covers abnormalities of kidney structure of function, present for $>3$ months, with implications for health [8]. All the patient must be in a stable clinical status. In the history of medication, excluded the patients if the they take drugs that affect uric acid metabolism within 2 weeks including diuretic, losartan, aspirin, glucocorticoids, cyclosporine, immunosuppressive agents, anti-tuberculosis drugs, sodium bicarbonate, levodopa, metformin, fenofibrate and UA-lowering agents, such as febuxostat, benzbromarone or allopurinol.

\section{Clinical and laboratory measurements}

Each participant was instructed to collect the urinary sample correctly. They were provided with a plastic bucket, following settled steps. It is noteworthy that 24-h urine collection must be done by discarding the first morning void and collecting all urine output for the next $24 \mathrm{~h}$, including the first morning void the next day. Well-trained nurses are responsible for recording the start and end of each specimen collection and using a standard questionnaire for complete interviews. To determine the accuracy of a 24-h urine collection, we designed two different ways to verify. First, total amount of urinary creatinine was measured in clinical laboratory, which was used to evaluate the adequacy. Considering that all patients were in CKD 1-2 stages, level less than $14 \mathrm{mg} / \mathrm{kg} /$ day in men and $11 \mathrm{mg} / \mathrm{kg} /$ day in women indicated inadequate collection. The second method compared discrepancy between the total amount of urinary creatinine measured and calculated. The calculated value was equal to total urine volume times the concentration of urinary creatinine, the former was recorded and measured after the collection, while the latter was measured by urine left at a certain point during this admission period. Adequacy was assessed at 20\% differences, such that any two values with a difference greater than the cutoffs described above would be considered inadequate. The urine collection that were judged inadequate would be traced back to the source and removed from the sample list. The two methods mentioned above were used to comprehensively evaluate the accuracy of a 24-hou urine collection.

Each sample was immediately sent to clinical laboratories for analysis of 24-h urinary levels of uric acid, creatine, sodium, potassium, glucose, albumin and urinary volume. So that we used the following indicators to estimate the excretion of uric acid and renal function. FEua was calculated as $(\mathrm{Uur} \times \mathrm{Scr}) /(\mathrm{SUA} \times \mathrm{Ucr}) \times 100$, expressed as percentage. Cur was calculated as Uur $\times$ UV/SUA. EurGF was calculated as (Uur $\times \mathrm{Scr}) / \mathrm{Ucr}$. Cur and EurGF were corrected for the body surface area.

The values of blood pressure were recorded by ambulatory blood pressure monitoring. Patients are randomly assigned two kinds of models (model ABPM 6100, produced by Welch Allyn, Inc. and model ABPM-05, produced by Meditech Ltd.). The blood pressure measurement and measurement accuracy of the two machines are same, but the measurement range of them has slightly difference, with the former ranging from $25 \mathrm{mmHg}-270 \mathrm{mmHg}$ and the latter ranging from 0 to $300 \mathrm{mmHg}$, which has no effect on the results. The monitoring interval is every $20 \mathrm{~min}$ during the daytime and $30 \mathrm{~min}$ during the night time in the two machines. Ambulatory blood pressure monitoring offers a special way of automated measurements of blood pressure during a 24-h period while patients are engaged in their usual activities, including the sleep. This type of measurement is superior to standard office measurement in getting more time points' value and more accurate data. We could obtain diverse data, such as average blood pressure, even the blood pressure coefficient of variation $(\mathrm{CV})$ of each time period and all day long. As an indicator for variability in 


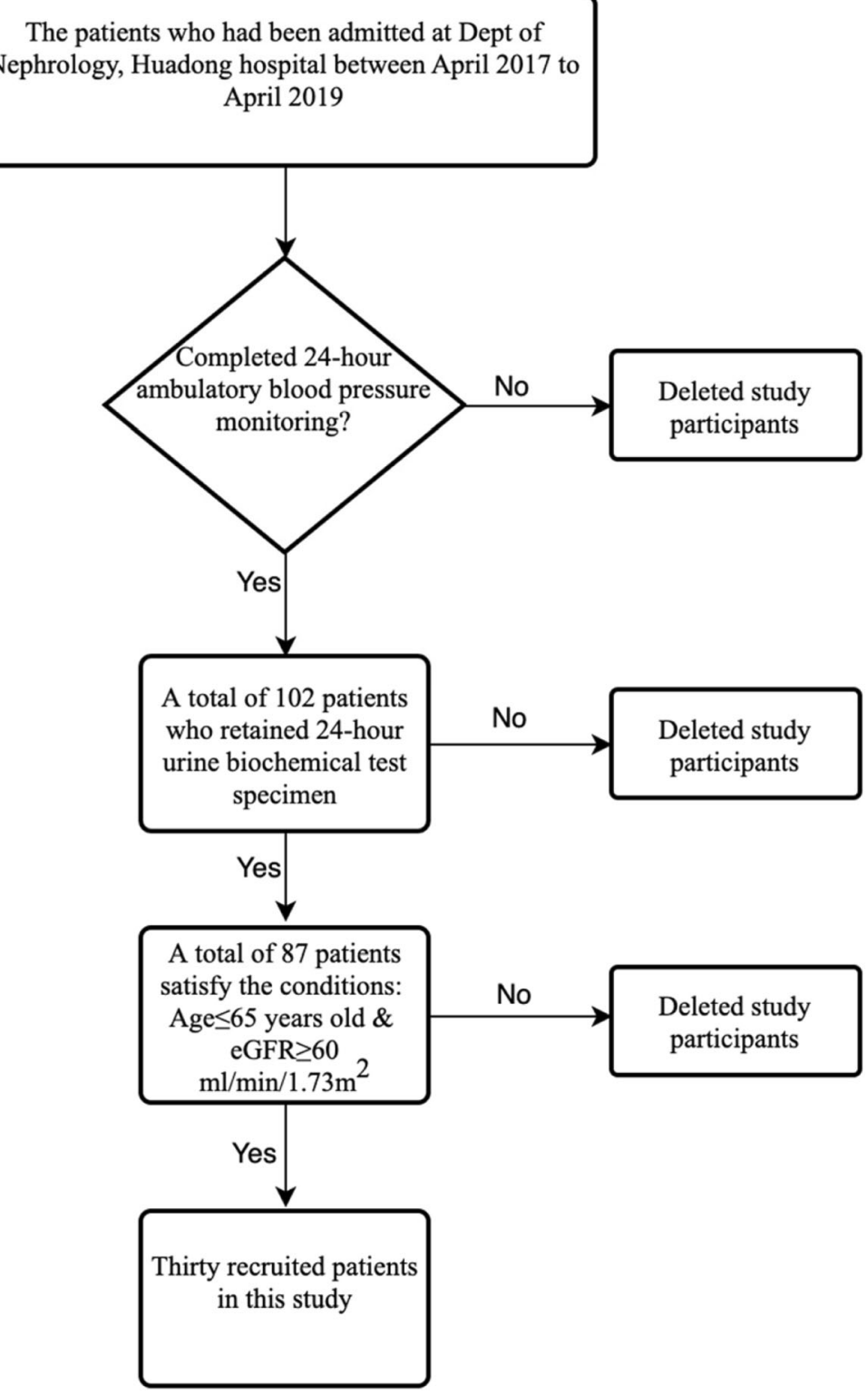

Fig. 1 Procedures for recruiting subjects

blood pressure, it is defined as $\mathrm{CV}$ of $\mathrm{BP}$ as standard deviation (s.d.) divided by corresponding average BP. Each day is divided into three periods, morning hours (6 a.m.-8 a.m.), daytime ( 8 a.m.-10 p.m.) and night time (10 p.m. to next 6 a.m.); average blood pressure in each period was separately abbreviated as mMSP, mMDP, dMSP, dMDP, nMSP and nMDP, for all day substituted for 24-h MSP and 24-h MDP.

After fasting for $12 \mathrm{~h}$ at night, each patient was taking venous blood for routine biochemical test by nurses. We could get symbols of each patient about the serum levels of uric acid (SUA), creatinine (Scr), urinary nitrogen (BUN), total cholesterol (TC), triglycerides (TG), highdensity lipoprotein (HDL), low-density lipoprotein
(LDL) and fasting blood glucose (FBG). The estimated glomerular filtration rate (eGFR) (milliliters per minute per $1.73 \mathrm{~m}^{2}$ ) was calculated by the Chronic Kidney Disease Epidemiology Collaboration (CKD-EPI) formula [9].

Height and weight were measured by well-trained nurses in a standard process. Body mass index (BMI) was calculated as weight in kilograms divided by height in meters squared.

\section{Diagnosis and grouping criteria}

Hypertension was defined as the average daytime blood pressure above 135/85 $\mathrm{mmHg}$, nighttime blood pressure above $120 / 70 \mathrm{mmHg}$, and $24-\mathrm{h}$ blood pressure above 
$130 / 80 \mathrm{mmHg}$ [10]; in clinical practice, it is generally considered that patients who are taking antihypertensive drugs have hypertension, especially BP that has been controlled after drug therapy, regardless of whether the $\mathrm{BP}$ is normal or not. Hyperuricemia was defined as the level of serum uric acid above $7 \mathrm{mg} / \mathrm{dl}$ in men and above $6 \mathrm{mg} / \mathrm{dl}$ in women in line with the recommendations of an epidemiology conference held in Rome in 1963 [11], which is widely accepted and applied.

Study participants were divided into two groups according to the median of FEua (FEua1: FEua $<6.0 \%$, FEua2: FEua $\geq 6.0 \%$ ) and Cur (Cur1: Cur $<6.2 \mathrm{ml} / \mathrm{min}$ / $1.73 \mathrm{~m}^{2}$; Cur2: Cur $\geq 6.2 \mathrm{ml} / \mathrm{min} / 1.73 \mathrm{~m}^{2}$ ).

\section{Statistical analysis}

The continuous variables are reported in mean \pm SD and categorical variables are presented in percentages. Medians with inter quartile range (IQR) are presented in case of nonparametric data. Comparisons between groups were made by Student's t-test and one-way ANOVA. Least significance difference (LSD) test was used when the variance was homogeneous, or Tamhane's T2 test was used. Nonnormally distributed data was compared using MannWhitney U test. Categorical data was compared using the Chi-square test. Correlations were detected by Pearson's or Spearman's depending on the distribution of the data. If Pearson's correlation analysis was statistically significant, multiple linear regression analysis was performed. Multiple linear regression analyses were performed to determine the association of urinary uric acid excretion with $24 \mathrm{~h}$ ambulatory blood pressure values. Statistical significance for all analyses was set at $P<0.05$. Statistical analysis was performed with software SPSS 22.0, Stata 14.0, and Prism 7.0a.

\section{Results}

\section{Characteristics of the study population}

This study embraced 30 participants with the age of approximately 53.40 years and with 21 males (70.0\%).
Causes of renal injury in 30 CKD patients were showed (Fig. 2). Eight of them had no hypertension and history of antihypertensive medication. CKD patients with hypertension were treated with calcium-channel blockers, $\beta$ blockers, angiotensin-converting enzyme inhibitors, angiotensin receptor blockers and selective $\alpha_{1}$ adrenergic receptor blockers, and there was no difference in the distribution of these drug between groups. The impression of data is shown in Table 1. Biochemical differences in two groups according to the median of FEua are also summarized in Table 1. Participants in the higher FEua group had higher Cur, EurGF, mMDP and nMDP than those in the lower FEua group (all $P<0.05$, Table 1). The distribution pattern of FEua was presented (Fig. 3).

\section{Association of urinary uric acid excretion with blood pressure values}

In order to study the association of the urinary uric acid excretion (FEua, Cur and EurGF) and 24-h blood pressure values (24-h MSP, 24-h MDP, mMSP, mMDP, dMSP, dMDP, nMSP, nMDP and CV of each period), all combinations are calculated after further permutations as shown below.

Pearson correlation analysis showed that FEua was positively associated with $\mathrm{MMDP}$, nMDP and $\mathrm{CV}$ of dMSP $(r=0.408, P=0.031 ; r=0.415, P=0.025 ; r=$ $0.413, P=0.023$, respectively), and not related to $24-\mathrm{h}$ mean blood pressure values and other relevant timeperiod values, including 24-h MSP $(r=0.219, P=0.244)$, 24-h MDP ( $r=0.264, P=0.159)$, CV of 24-h MSP and $\operatorname{MDP}(r=0.253, P=0.177 ; r=0.200, P=0.289)$, mMSP $(r=0.253, P=0.194), \mathrm{CV}$ of mMSP and mMDP $(r=$ $0.007, P=0.971 ; r=-0.096, P=0.628)$, dMSP $(r=$ 0.132, $P=0.488)$, dMDP $(r=0.170, P=0.370)$, CV of dMDP $(r=0.304, P=0.102$, nMSP $(r=0.328, P=0.082)$, CV of nMSP and nMDP $(r=0.172, P=0.373 ; r=0.098$, $P=0.613)$. There was a positive correlation between Cur and CV of dMSP $(r=0.408, P=0.028)$.

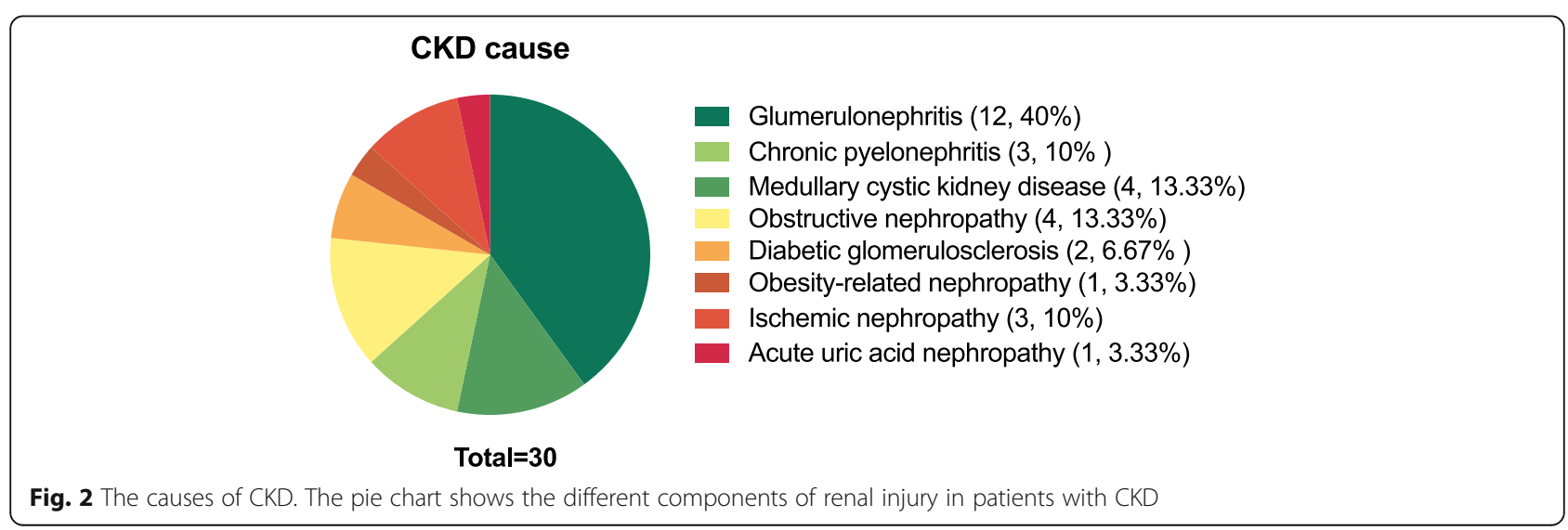


Table 1 Characteristics of the study population according to median of FEua

\begin{tabular}{|c|c|c|c|c|}
\hline \multirow[t]{2}{*}{ Variables } & \multirow[t]{2}{*}{$\begin{array}{l}\text { All } \\
(n=30)\end{array}$} & \multirow{2}{*}{$\begin{array}{l}\text { FEua1 } \\
(n=15) \\
<6.0 \%\end{array}$} & \multirow{2}{*}{$\begin{array}{l}\text { FEua2 } \\
(n=15) \\
\geq 6.0 \%\end{array}$} & \multirow[t]{2}{*}{$P$ value } \\
\hline & & & & \\
\hline Males gender (\%) & 70.00 & 66.7 & 73.30 & 0.500 \\
\hline Age(years) & $53.50(35.75,58.25)$ & $50.00(31.00,58.00)$ & $55.00(38.00,59.00)$ & 0.184 \\
\hline $\mathrm{BMI}\left(\mathrm{kg} / \mathrm{m}^{2}\right)$ & $24.33(21.67,26.33)$ & $25.01(21.30,29.75)$ & $24.16(22.49,25.44)$ & 0.226 \\
\hline eGFR (ml/min/1.73 m²) & $82.45(69.08,98.68)$ & $81.60(66.00,99.80)$ & $82.90(71.50,98.30)$ & 0.298 \\
\hline SUA (umol/L) & $366.30 \pm 96.81$ & $396.93 \pm 94.99$ & $335.67 \pm 91.55$ & 0.083 \\
\hline $\mathrm{TC}(\mathrm{mmol} / \mathrm{L})$ & $4.31(3.95,4.95)$ & $4.50(4.00,5.05)$ & $4.28(3.71,5.08)$ & 0.215 \\
\hline $\mathrm{TG}(\mathrm{mmol} / \mathrm{L})$ & $2.10(1.00,2.80)$ & $2.50(1.33,3.13)$ & $1.80(1.00 .2 .25)$ & 0.140 \\
\hline 24-hUV(mL) & $1631.78 \pm 799.96$ & $1610.03 \pm 875.23$ & $1653.52 \pm 702.19$ & 0.882 \\
\hline 24-hUua(mmol) & $3.18 \pm 1.16$ & $2.81 \pm 1.10$ & $3.56 \pm 1.13$ & 0.077 \\
\hline 24-hUpro(mmol) & $0.33 \pm 0.66$ & $0.47 \pm 0.89$ & $0.19 \pm 0.28$ & 0.255 \\
\hline Cur $\left(\mathrm{ml} / \mathrm{min} / 1.73 \mathrm{~m}^{2}\right)$ & $6.10 \pm 2.04$ & $5.09 \pm 1.99$ & $7.19 \pm 1.49^{* *}$ & 0.003 \\
\hline EurGF (mg/dL/1.73 m²) & $21.21 \pm 5.98$ & $17.05 \pm 3.45$ & $25.37 \pm 5.01^{* *}$ & $<0.001$ \\
\hline $\mathrm{Ccr}\left(\mathrm{ml} / \mathrm{min} / 1.73 \mathrm{~m}^{2}\right)$ & $103.62 \pm 29.54$ & $113.72 \pm 32.37$ & $92.79 \pm 22.52$ & 0.055 \\
\hline $24 \mathrm{~h}$ MSP $(\mathrm{mmHg})$ & $124.00(119.00,132.50)$ & $125.00(119.00,130.00)$ & $124.00(119.00,140.00)$ & 0.256 \\
\hline $24 \mathrm{~h}$ MDP $(\mathrm{mmHg})$ & $77.07 \pm 10.52$ & $74.00 \pm 9.64$ & $80.13 \pm 10.78$ & 0.112 \\
\hline mMSP (mmHg) & $127.82 \pm 11.93$ & $123.79 \pm 11.11$ & $131.86 \pm 11.71$ & 0.073 \\
\hline $\mathrm{mMDP}(\mathrm{mmHg})$ & $79.86 \pm 11.23$ & $74.93 \pm 8.78$ & $84.79 \pm 11.51^{*}$ & 0.017 \\
\hline dMSP (mmHg) & $129.47 \pm 13.71$ & $127.33 \pm 11.90$ & $131.60 \pm 15.43$ & 0.195 \\
\hline $\mathrm{dMDP}(\mathrm{mmHg})$ & $77.00(72.50,83.00)$ & $77.00(68.00,82.00)$ & $77.00(74.00,86.00)$ & 0.173 \\
\hline nMSP (mmHg) & $116.00(110.00,125.50)$ & $115.00(110.00,123.00)$ & $122.00(110.00,136.50)$ & 0.101 \\
\hline nMDP (mmHg) & $72.55 \pm 10.99$ & $68.00 \pm 846$ & $77.43 \pm 11.55^{* *}$ & 0.0018 \\
\hline
\end{tabular}

${ }^{*} P<0.05,{ }^{* *} P<0.01$ vs. the FEua1 using the Independent-Sample Test (T-test) method if the variance is equal or the Tamhane's T2 method when the variance is not equal, using Mann-Whitney $\mathrm{U}$ test in case of nonparametric data distribution. Numbers are mean \pm SD or proportion. For age, BMI, eGFR, TC, TG, $24 \mathrm{~h}$ MSP, $\mathrm{dMDP}$ and $\mathrm{nMDP}$, median and the 25th and 75th percentile are shown

Abbreviations: BMI Body mass index, eGFR Estimated glomerular filtration rate, SUA Serum uric acid, TC Total cholesterol, TG Triglycerides, 24-h UV 24-h urinary volume, 24-h Uua 24-h urinary uric acid, 24-h Upro 24-h urinary protein, Cur Uric acid clearance rate, EurGF Excretion of uric acid per volume of glomerular filtration, $C c r$ Creatinine clearance, 24- $h$ MSP 24-h mean systolic pressure, 24- $h$ MDP 24-h mean diastolic pressure, $m M S P$ Morning mean systolic pressure, $m M D P$ Morning mean diastolic pressure, $d M S P$ Day mean systolic pressure, $d M D P$ Day mean diastolic pressure, $n M S P$ Night mean systolic pressure, $n M D P$ Night mean diastolic pressure

Boldface significant differences between FEua1 and FEua2

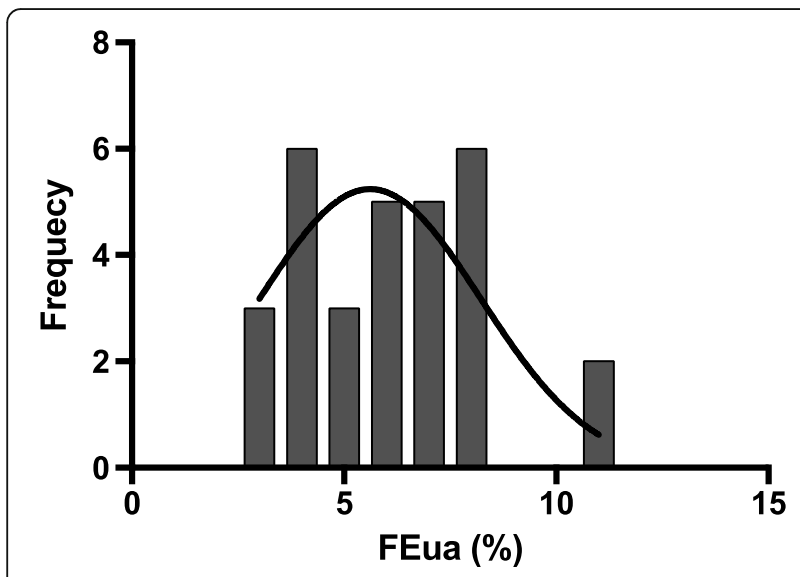

Fig. 3 The distribution of FEua. The median value of FEua is approximately 6\%
Multiple linear regression analysis showed that FEua was still positively associated with the mMDP and nMDP after adjusting confounding factors [model 1 adjusted for age and BMI; model 2 plus gender and urine albumin to creatinine ratio (ACR); model 3 plus eGFR, TC and TG) (all $P<0.05$, Table 2)]. However, the association of FEua and CV of dMSP disappeared $(P>0.05)$. Multiple linear regression analysis showed that Cur was still positively associated with CV of dMSP after adjusting confounding factors (model 1 adjusted for age and BMI; model 2 plus gender and ACR; model 3 plus eGFR, TC and TG) (all $P<0.05$, Table 2).

\section{Differences of mMDP, nMDP in FEua groups and CV of dMSP in Cur groups}

Compared with the higher FEua group, levels of mMDP and nMDP in the lower group (FEua $<6.0 \%)$ was lower than that in the higher FEua2 (FEua $\geq 6.0 \%$ ) group (both 
Table 2 Multiple linear regression analysis for the association of mMDP and nMDP (independent variable) with FEua (dependent variable) and the association of CV of dMSP (independent variable) with FEua and Cur (dependent variable)

\begin{tabular}{|c|c|c|c|c|c|c|c|c|c|c|c|c|}
\hline & \multicolumn{3}{|l|}{ Model 1} & \multirow[t]{2}{*}{$A d j R^{2}$} & \multicolumn{3}{|l|}{ Model 2} & \multirow[t]{2}{*}{$A d j R^{2}$} & \multicolumn{3}{|l|}{ Model 3} & \multirow[t]{2}{*}{$\operatorname{Adj} R^{2}$} \\
\hline & B & SE & P & & B & SE & $P$ & & $B$ & $S E$ & $P$ & \\
\hline \multicolumn{13}{|l|}{ FEua: } \\
\hline mMDP & 209.965 & 97.401 & 0.042 & 0.061 & 215.506 & 98.255 & 0.042 & 0.078 & 463.929 & 134.082 & 0.005 & 0.413 \\
\hline nMDP & 214.828 & 93.775 & 0.031 & 0.128 & 273.428 & 99.687 & 0.013 & 0.229 & 416.231 & 153.804 & 0.019 & 0.313 \\
\hline CV of dMSP & 0.762 & 0.338 & 0.033 & 0.074 & 0.914 & 0.334 & 0.013 & 0.113 & 1.154 & 0.550 & 0.056 & 0.125 \\
\hline \multicolumn{13}{|l|}{ Cur: } \\
\hline CV of dMSP & 0.08 & 0.004 & 0.037 & 0.067 & 0.009 & 0.004 & 0.033 & 0.032 & 0.012 & 0.004 & 0.011 & 0.297 \\
\hline
\end{tabular}

Model 1 adjusted for age and BMl; model 2 plus gender and ACR; model 3 plus eGFR, TC and TG. Beta coefficients refer to how many deviations a dependent variable will change per deviation increase in the predictor variable. SE refers to standard error. The adjust $R^{2}$ represents the goodness of fit, which is used to measure the degree of the estimated models fitting the observations

Abbreviations: FEua Fractional excretion of uric acid, $m M D P$ Morning mean diastolic pressure, nMDP Night mean diastolic pressure, CV of dMSP Coefficient of variation of day mean systolic pressure, Cur Uric acid clearance rate, BMI Body mass index, ACR Albumin-to-creatinine ratio, eGFR Estimated glomerular filtration rate, TC Total cholesterol, TG Triglycerides

$P<0.05$, Fig. 4a and b). Level of CV of dMSP in the higher Cur2 (Cur $\geq 6.2 \mathrm{ml} / \mathrm{min} / 1.73 \mathrm{~m}^{2}$ ) group were higher than that in the lower Cur1 (Cur $<6.2 \mathrm{ml} / \mathrm{min}$ / $\left.1.73 \mathrm{~m}^{2}\right)$ group $(P<0.01$, Fig. $4 \mathrm{c})$.

\section{Discussion}

This study putted forward a comprehensive analysis of the association of urinary uric acid excretion with ambulatory BP values in CKD 1-2 patients. FEua and Cur, as markers for urinary uric acid excretion, were associated with the representative ambulatory blood pressure values. To the best of our knowledge, this study is the first to show a positive correlation of FEua with morning mean diastolic pressure and night mean diastolic pressure respectively.

Uric acid levels have been demonstrated to be correlated with blood pressure. According to our previous research [6], in the population with CKD and hypertension, fraction excretion of sodium (FEna) was negatively correlated with 24-h urinary uric acid and clearance of uric acid and positively correlated with FEua; urinary sodium/potassium ratio (Una/k) was negatively associated with $24-\mathrm{h}$ Uua and Cur, and positively associated with FEua. To a large extent, these results suggest that the excretion of urinary sodium and potassium is closely related to the ability of the kidneys to process and excrete uric acid. So far what we know is that the excretion of urinary sodium and potassium is positively related to hypertension $[12,13]$. In the previous basic study, we found that uric acid plays a down-regulated function in the NKA activity and its $\alpha 1$ subunit subcellular expression as well as the descending of the intracellular ATP, cell injury and the further activation of Src, NLRP3 and IL-1 $\beta$ [7]. Further, dysfunctional NKA caused by defected membrane of renal tubular cells result in diminished $\mathrm{Na}^{+}$reabsorption and urinary concentration ability [14]. In other words, incremental urinary sodium excretion leads to hypertension [15]. All above is expected to prove that the extent of urinary uric acid excretion, whether it takes the form of FEua or Cur, may be related with the value of blood pressure.
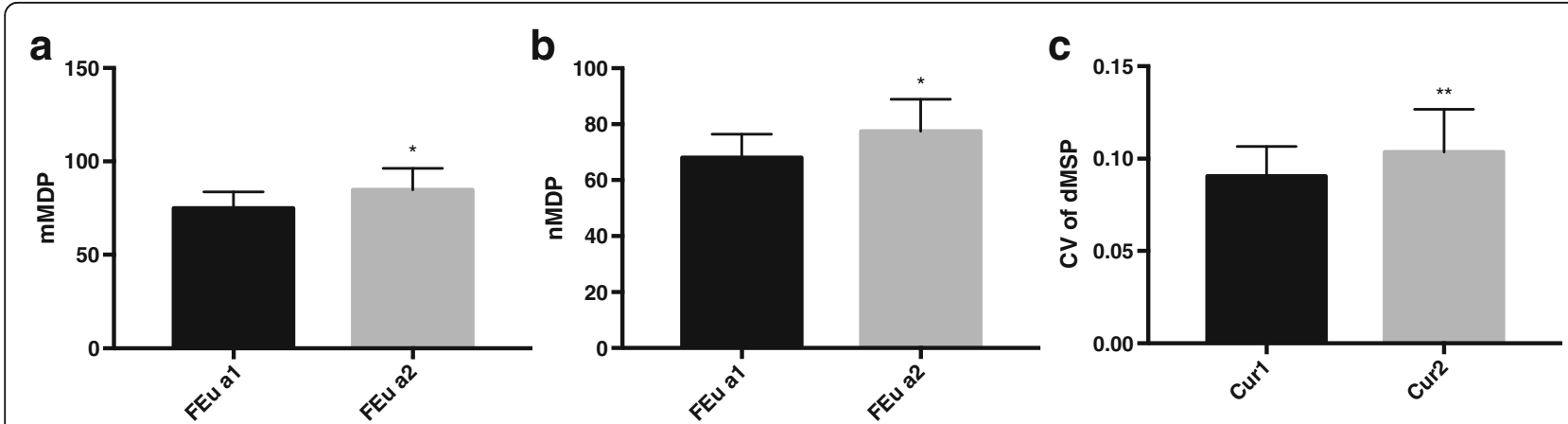

Fig. 4 Differences of mMDP, nMDP in FEua groups and CV of dMSP in Cur groups. Levels of the values of mMDP, nMDP and CV of dMSP were compared according to the median of FEua by independent sample T test. With the higher FEua2 (FEua $\geq 6.0 \%$ ) group, the values of mMDP and nMDP went higher (both $P<0.05$ ) than that of FEua1 (FEua<6.0\%). Level of CV of dMSP was compared according to the median of Cur by independent sample T test. With the higher Cur2 (Cur $\left.\geq 6.2 \mathrm{ml} / \mathrm{min} / 1.73 \mathrm{~m}^{2}\right)$ group, the values of CV of dMSP went higher $(P<0.01)$ than that of Cur1 (Cur $<6.2 \mathrm{ml} / \mathrm{min} / 1.73 \mathrm{~m}^{2}$ ) 
Diastolic blood pressure is more closely related to uric acid levels. As we all know, systolic blood pressure is the pressure on the blood vessels when the heart contracts, while the diastolic blood pressure is generated by the elastic retraction of arteries. Therefore, diastolic blood pressure is more dependent on the elasticity and resistance of the blood vessel wall. In the Maastricht study [16], it is clear that serum uric acid and urinary uric acid excretion were associated with $24 \mathrm{~h}$ mean arterial pressure (MAP) but not with $24 \mathrm{~h}$ pulse pressure (PP). Similarly, diastolic blood pressure increases significantly as serum uric acid increases among children [17]. MAP is the steady component of BP reflecting vascular resistance, which can be increased by inhibiting the vasodilator nitric oxide $[18,19]$. Reactive oxygen species (ROS) are produced during generation of uric acid. Xanthine oxidoreductase catalyzes the decomposition of xanthine into xanthine and xanthine into uric acid. When oxygen is an electron acceptor, superoxide radical anions $\left(\mathrm{O}^{2-}\right)$ and hydrogen peroxide $\left(\mathrm{H}_{2} \mathrm{O}_{2}\right)$ are produced as byproducts of the oxidation step [20]. These ROS directly decrease the bioavailability of the vasodilator nitric oxide and lead to the formation of peroxynitrite, which can increase the uncoupling of endothelial nitric oxide synthase, leading to more ROS. These changes are more intuitively reflected in the elasticity and resistance of blood vessels, which may explain why only diastolic blood pressure is elevated.

Some mechanisms may be responsible for the positive correlation of FEua with morning and night mean diastolic pressure, which had a special time range. Variations in blood pressure show a diurnal change, a surge in the morning and a decrease in sleeping time. The differences in blood pressure over the course of the day are due to circadian changes, and more specifically, behavioral changes in activity and rest (such as posture and meal times, psychological activity and sleeping), external environment (including ambient temperature and noise levels) and endogenous circadian rhythms in hemodynamic, endocrine, endothelial and neural variables, such as plasma noradrenaline and adrenaline levels (the autonomic nervous system), and renin, angiotensin and aldosterone levels (the renin-angiotensin-aldosterone system) [21-24]. RNA-seq analysis of mouse tissues revealed that the kidney is second only to the liver in the number of genes expressed in a circadian pattern [25]. Circulating levels of Ang II and aldosterone have a diurnal variation in humans, with higher plasma concentrations in the morning [26-28]. For the former, it binds to the correspond receptors to affect several systems and stimulates the blood pressure by constricting the blood vessels. Aldosterone, generated in the zona glomerulosa of adrenal cortex, plays a role in increasing the reabsorption of $\mathrm{Na}^{+}$ and secretion of $\mathrm{K}^{+}$. As we said before, the change of excretion of sodium and potassium is responsible for the increasing of blood pressure. Moreover, molecular clock in renal function plays a major role, which manifested in the renal excretion of water and major electrolytes [29]. What we already knew is that the excretion of uric acid is related to the major electrolytes in human body, including $\mathrm{Na}^{+}$and $\mathrm{K}^{+}$. When dietary purine intake was kept constant, monophasic circadian fluctuations of fractional urate excretion (FEua) were observed with peak values in the afternoon, about $50 \%$ higher than during the night [30]. Due to the decreased excretion of uric acid in the nighttime, an upward trend may be shown in the serum uric acid. Thus, elevated serum UA levels can affect the development of rising blood pressure value [31]. Experimental studies have shown that raising serum UA can induce hypertension by stimulating oxidative stress, impairing endothelial function, and stimulating the renin angiotensin system [32, 33]. Furthermore, it also associated with morning blood pressure surge [34].

Cur, as a parameter to measure the uric acid removed from body, is positively related to CV of dMSP. In this research, the variability of blood pressure is not simply described as the standard deviation (SD) of the 24-h, morning, daytime and nighttime mean values obtained by using ambulatory BP monitoring, it was calculated as standard deviation (s.d.) divided by corresponding average BP called coefficient of variation of blood pressure (CV of BP). As proved in the prior study, SUA levels are independently associated with different BPV (the standard deviation of each time period) components in a population of newly diagnosed patients with essential hypertension [4]. With urinary uric acid excretion increased, SUA may fluctuate caused by dysfunction of renal handling of uric acid. As is discussed above, CV of dMSP is more sensitive to reflect the tiny fluctuations, especially during the active daytime.

This study had several potential limitations. First of all, the sample size is relatively small and there may be considerable deviations. Second, the values of blood pressure are generally not high, and some patients have accepted the antihypertensive treatment. Other limitations of this study include its cross-sectional design and one-time ABPM. Since the study explored the correlation between urinary uric acid excretion with blood pressure, antihypertensive treatment will affect the results of the observation and detection.

\section{Conclusion}

In summary, we demonstrated that there is a positive correlation of FEua with morning and night mean diastolic pressure separately and Cur is positively related to CV of dMSP in CKD population. Monitoring the trend of urinary uric acid, may have a role in the early detection for hypertension or relative risks in the population of CKD. More researches are needed to elucidate mechanism underlying higher urinary uric acid excretion leading to hypertension. 


\section{Abbreviations}

ABPM: Ambulatory BP monitoring; ACR: Urine albumin to creatinine ratio; BMI: Body mass index; BPV: Blood pressure variability; BUN: Urinary nitrogen; CKD: Chronic kidney disease; Cur: Uric acid clearance rate; CV of dMSP: Coefficient of variation of day mean systolic pressure; eGFR: Estimated glomerular filtration rate; EurGF: Excretion of uric acid per volume of glomerular filtration; FBG: Fasting blood glucose; FEna: Fraction excretion of sodium; FEua: Fractional excretion of uric acid; HDL: High-density lipoprotein; HTN: Hypertension; IQR: Medians with inter quartile range; LDL: Low-density lipoprotein; LSD: Least significance difference; MAP: Mean arterial pressure; MBPS: Morning blood pressure surge; mMDP: Morning mean systolic pressure; NKA: $\mathrm{Na}^{+}-\mathrm{K}^{+}$-ATPase; nMDP: Night mean diastolic pressure; PP: Pulse pressure; ROS: Reactive oxygen species; Scr: Creatinine; SD: Standard deviation; SUA: Uric acid; TC: Total cholesterol; TG: Triglycerides; Una/k: Urinary sodium/potassium ratio

\section{Acknowledgements}

Not applicable.

\section{Authors' contributions}

$Y X, X Z, Y Z$ and $H G$ collected the patient data regarding the study. YX performed the analyzation and interpretation, and was a major contributor in writing the manuscript. CF, JX and ZY provided ideas and guidance. All authors read and approved the final manuscript.

\section{Funding}

Not applicable.

\section{Availability of data and materials}

The datasets generated and analyzed during the current study are not publicly available due patient privacy but are available from the corresponding author on reasonable request.

\section{Ethics approval and consent to participate}

This research accepted the ethics approval and consent from Ethics Committee of Huadong Hospital (the committee's reference number: 2019 k063).

\section{Consent for publication}

Not applicable.

\section{Competing interests}

The authors declare that they have no competing interests.

\section{Author details}

'Department of Nephrology, Huadong Hospital Affiliated to Fudan University, No. 221 West Yan'an Road, Shanghai 200040, People's Republic of China. ${ }^{2}$ Shanghai Key Laboratory of Clinical Geriatric Medicine, No. 221 West Yan'an Road, Shanghai 200040, People's Republic of China.

Received: 23 July 2019 Accepted: 8 January 2020

Published online: 15 February 2020

\section{References}

1. Kario K. Morning surge in blood pressure and cardiovascular risk: evidence and perspectives. Hypertension. 2010;56(5):765-73.

2. Kario K, Kanegae H, Tomitani N, Okawara Y, Fujiwara T, Yano Y, et al. Nighttime blood pressure measured by home blood pressure monitoring as an independent predictor of cardiovascular events in general practice. Hypertension. 2019. https://doi.org/10.1161/HYPERTENSIONAHA.118.12740.

3. Mena LJ, Felix VG, Melgarejo JD, Maestre GE. 24-hour blood pressure variability assessed by average real variability: a systematic review and meta-analysis. J Am Heart Assoc. 2017;6(10). https://doi.org/10.1161/JAHA.117.006895.

4. Cagli K, Turak O, Canpolat U, Ozcan F, Tok D, Mendi MA, et al. Association of serum uric acid level with blood pressure variability in newly diagnosed essential hypertension. J Clin Hypertens (Greenwich). 2015;17(12):929-35.

5. Liu H, Zhang XM, Wang YL, Liu BC. Prevalence of hyperuricemia among Chinese adults: a national cross-sectional survey using multistage, stratified sampling. J Nephrol. 2014;27(6):653-8.
6. Li F, Guo H, Zou J, Chen W, Lu Y, Zhang X, et al. The association of urinary sodium and potassium with renal uric acid excretion in patients with chronic kidney disease. Kidney Blood Press Res. 2018;43(4):1310-21.

7. Xiao J, Zhang X, Fu C, Yang Q, Xie Y, Zhang Z, et al. Impaired $\mathrm{Na}(+)-\mathrm{K}(+$ )-ATPase signaling in renal proximal tubule contributes to hyperuricemiainduced renal tubular injury. Exp Mol Med. 2018;50(3):e452.

8. Eknoyan G, Lameire N, Eckardt K, Kasiske B, Wheeler D, Levin A, et al. KDIGO 2012 clinical practice guideline for the evaluation and management of chronic kidney disease. Kidney Int. 2013;3(1):5-14.

9. Stevens PE, Levin A, Kidney Disease: Improving Global Outcomes Chronic Kidney Disease Guideline Development Work Group M. Evaluation and management of chronic kidney disease: synopsis of the kidney disease: improving global outcomes 2012 clinical practice guideline. Ann Intern Med. 2013;158(11):825-30.

10. Williams B, Mancia G, Spiering W, Agabiti Rosei E, Azizi M, Burnier M, et al. 2018 ESC/ESH guidelines for the management of arterial hypertension. Eur Heart J. 2018;39(33):3021-104.

11. Bardin T, Richette P. Definition of hyperuricemia and gouty conditions. Curr Opin Rheumatol. 2014:26(2):186-91.

12. Mente A, O'Donnell MJ, Rangarajan S, McQueen MJ, Poirier P, Wielgosz A, et al. Association of urinary sodium and potassium excretion with blood pressure. N Engl J Med. 2014;371(7):601-11.

13. Mills KT, Chen J, Yang W, Appel LJ, Kusek JW, Alper A, et al. Sodium excretion and the risk of cardiovascular disease in patients with chronic kidney disease. JAMA. 2016;315(20):2200-10.

14. Oliveira FS, Vieira-Filho LD, Cabral EV, Sampaio LS, Silva PA, Carvalho VC, et al. Reduced cholesterol levels in renal membranes of undernourished rats may account for urinary $\mathrm{Na(+)} \mathrm{loss.} \mathrm{Eur} \mathrm{J} \mathrm{Nutr.} \mathrm{2013;52(3):1233-42.}$

15. Wang D, Wang Y, Liu FQ, Yuan ZY, Mu JJ. High salt diet affects renal sodium excretion and ERRalpha expression. Int J Mol Sci. 2016;17(4):480.

16. Scheepers LEJM, Boonen A, Dagnelie PC, Schram MT, van der Kallen CJH, Henry RMA, et al. Uric acid and blood pressure. J Hypertens. 2017;35(10):1968-75.

17. Jones DP, Richey PA, Alpert BS, Li R. Serum uric acid and ambulatory blood pressure in children with primary hypertension. Pediatr Res. 2008;64(5):556-61.

18. Zhang JX, Zhang YP, Wu QN, Chen B. Uric acid induces oxidative stress via an activation of the renin-angiotensin system in 3T3-L1 adipocytes. Endocrine. 2015;48(1):135-42.

19. Corry DB, Eslami P, Yamamoto K, Nyby MD, Makino H, Tuck ML. Uric acid stimulates vascular smooth muscle cell proliferation and oxidative stress via the vascular renin-angiotensin system. J Hypertens. 2008;26(2):269-75.

20. McCord JM, Fridovich I. The reduction of cytochrome $\mathrm{c}$ by milk xanthine oxidase. J Biol Chem. 1968:243(21):5753-60.

21. Hermida RC, Ayala DE, Portaluppi F. Circadian variation of blood pressure: the basis for the chronotherapy of hypertension. Adv Drug Deliv Rev. 2007; 59(9-10):904-22.

22. Fabbian F, Smolensky MH, Tiseo R, Pala M, Manfredini R, Portaluppi F. Dipper and non-dipper blood pressure 24-hour patterns: circadian rhythmdependent physiologic and pathophysiologic mechanisms. Chronobiol Int. 2012;30(1-2):17-30.

23. Portaluppi F, Tiseo R, Smolensky MH, Hermida RC, Ayala DE, Fabbian F. Circadian rhythms and cardiovascular health. Sleep Med Rev. 2012;16(2):151-66.

24. Smolensky MH, Hermida RC, Castriotta RJ, Portaluppi F. Role of sleep-wake cycle on blood pressure circadian rhythms and hypertension. Sleep Med. 2007;8(6):668-80.

25. Zhang $\mathrm{R}$, Lahens NF, Ballance $H \mathrm{H}$, Hughes ME, Hogenesch JB. A circadian gene expression atlas in mammals: implications for biology and medicine. Proc Natl Acad Sci U S A. 2014;111(45):16219-24.

26. Johnston JG, Pollock DM. Circadian regulation of renal function. Free Radic Biol Med. 2018;119:93-107.

27. Hurwitz S, Cohen RJ, Williams GH. Diurnal variation of aldosterone and plasma renin activity: timing relation to melatonin and cortisol and consistency after prolonged bed rest. J Appl Physiol (1985). 2004;96(4):1406-14

28. Rittig S, Matthiesen TB, Pedersen EB, Djurhuus JC. Circadian variation of angiotensin II and aldosterone in nocturnal enuresis: relationship to arterial blood pressure and urine output. J Urol. 2006;176(2):774-80.

29. Zuber AM, Centeno G, Pradervand S, Nikolaeva S, Maquelin L, Cardinaux L, et al. Molecular clock is involved in predictive circadian adjustment of renal function. Proc Natl Acad Sci U S A. 2009;106(38):16523-8.

30. Ter Maaten JC, Voorburg A, Heine RJ, Ter Wee PM, Donker AJ, Gans RO. Renal handling of urate and sodium during acute physiological hyperinsulinaemia in healthy subjects. Clin Sci (Lond). 1997;92(1):51-8. 
31. Giallauria F, Predotti P, Casciello A, Grieco A, Russo A, Viggiano A, et al. Serum uric acid is associated with non-dipping circadian pattern in young patients (30-40 years old) with newly diagnosed essential hypertension. Clin Exp Hypertens. 2016;38(2):233-7.

32. Sanchez-Lozada LG, Tapia E, Lopez-Molina R, Nepomuceno T, Soto V, AvilaCasado $C$, et al. Effects of acute and chronic $L$-arginine treatment in experimental hyperuricemia. Am J Physiol Renal Physiol. 2007;292(4):F1238-44.

33. Sanchez-Lozada LG, Soto V, Tapia E, Avila-Casado C, Sautin YY, Nakagawa T, et al. Role of oxidative stress in the renal abnormalities induced by experimental hyperuricemia. Am J Physiol Renal Physiol. 2008;295(4):F1134-41.

34. Turak O, Afsar B, Ozcan F, Canpolat U, Grbovic E, Mendi MA, et al. Relationship between elevated morning blood pressure surge, uric acid, and cardiovascular outcomes in hypertensive patients. J Clin Hypertens (Greenwich). 2014;16(7):530-5.

\section{Publisher's Note}

Springer Nature remains neutral with regard to jurisdictional claims in published maps and institutional affiliations.

Ready to submit your research? Choose BMC and benefit from:

- fast, convenient online submission

- thorough peer review by experienced researchers in your field

- rapid publication on acceptance

- support for research data, including large and complex data types

- gold Open Access which fosters wider collaboration and increased citations

- maximum visibility for your research: over $100 \mathrm{M}$ website views per year

At BMC, research is always in progress.

Learn more biomedcentral.com/submissions 